\title{
VIOLATION OF GRICE'S MAXIMS AND AMBIGUITY IN ENGLISH LINGUISTIC JOKES
}

\author{
Ilham Taghiyev \\ PhD student, Khazar University, Azerbaijan, itagiyev@khazar.org
}

\begin{abstract}
The English believe that being English is first of all having a good sense of humor. Therefore, a shameful thing for them is to be regarded as a person with no sense of humor. Thus, English humor, which is very sophisticated, aristocratic and subtle, is widely used in their everyday life. This paper aims to find out the relationship between the violation of Grice's maxims and the ambiguity that induce humor and laughter in each case of violation.
\end{abstract}

The present paper studies the types of ambiguity which are the most popular device in the process of creation of English linguistic verbal jokes matching them to the violation of Grice's maxims that form an important constituent of linguistic verbal jokes. First, Grice's Cooperative Principles, their violation and the way how they are violated are considered. Then, ambiguity in English linguistic jokes is defined and categorized. After that, ten randomly chosen English linguistic jokes (five lexical-semantic and five structuralsyntactic jokes respectively) are analyzed demonstrating the violation and the manner of violation of Grice's maxims in them.

If people said exactly what they meant, and if people understood their interlocutors' intention and interpreted what they heard correctly, there would be no linguistic humor. According to American philosopher Paul Grice, people observe certain cooperative principle to conduct successful interaction. Thus, Grice suggests four main maxims (or super maxims) viz. maxims of quantity, quality, relation and manner within his famous Cooperative Principles, the violation of which can cause misunderstanding that is one of the main sources of linguistic jokes. The above four super maxims can be violated in four ways: 1) quietly and unostentatiously, 2) by opting out of a maxim, 3) coping with a clash between maxims, and 4) flouting a maxim in order to exploit it. (Grice, 1975, pp. 45-49).

In linguistics, ambiguity is defined as words, phrases or sentences that express more than one meaning. (Crystal, 2008, p.22). According to another definition, ambiguity is a construction which admits more than one interpretation. Salvatore Attardo et al. (1994), in their study of a corpus of two thousand jokes, found out that four hundred and thirty-one of the four hundred and forty-one verbal jokes, i. e. about ninety-eight percent, were ambiguity based. Ambiguity itself falls two main types - lexical-semantic and structuralsyntactic. In the first case, any word or sentence has more than one meaning, in the second case, the role of any word or its relation with other constituents in the sentence has more than one possibility.

In linguistic jokes, the humorous effect is achieved through lexical-semantic or structural-syntactic ambiguity where Grice's maxims are violated. Thus, the main conclusion will be as follows:

In the first line of two-linear verbal linguistic jokes, Grice's maxims of quantity (make your contribution as informative as required) and manner (avoid ambiguity) are violated. In the second line (punch line), Grice's maxims of relation (be relevant) and manner (avoid ambiguity) are violated. Maxims of quantity and manner 
are violated quietly and unostentatiously, whereas maxim of relation is violated by flouting the maxim.

The present study paves the way for future studies in terms of finding out the relationship between types of ambiguity in verbal linguistic jokes on the one hand, and the violation of Grice's maxims in these jokes and manner of this violation on the other.

Keywords: Grice's maxims, English humor, Linguistic jokes, ambiguity

\section{TYPES OF AMBIGUITY AND HUMOR ANALYSIS}

If linguistic jokes are investigated more thoroughly, it can be observed that it is ambiguity that induces humor. In English linguistic jokes, ambiguity exists at all levels of language viz. phonological, morphological, semantic and syntactic levels. Therefore, it can be considered the most productive source of linguistic jokes. As it was stated above, ambiguity has two main types - lexical-semantic ambiguity and structural-syntactic ambiguity. In the first case any word, phrase or sentence has more than one meaning, in the second case the role of any word or its relation with other constituents of the sentence has more than one possibility. All other subcategories of ambiguity mentioned by scholars belong either to the first, or to the second type. Therefore, classifying linguistic jokes according to the types of ambiguity, they are categorized into lexicalsemantic and structural-syntactic ones, respectively.

\subsection{Lexical-semantic Jokes}

As it was mentioned above, lexical-semantic humor occurs when a word or a phrase in the sentence has more than one meaning causing ambiguity. This intentional or unintentional misinterpretation induces humor and laughter as in the following jokes.

Judge: Order! Order! Order in the court!

Prisoner: l'll take ham sandwich on rye and beer!

(Gao C., 2013, p.668)

In this joke, the word 'order' has two meanings. One is 'call to order' as a command, the other is 'to order food' which is not appropriate in this situation. In spite of this, the prisoner intentionally misinterprets it and the situation becomes humorous.

Diner: Waiter, l'm in a hurry. Will the cakes be long?

Waiter: No, sir. They will be round.

(Gao C., 2013, p.668)

Here the word 'long' can be interpreted as having two different meanings: a) as an antonym for 'short' referring to an object and b) as an antonym for 'short' referring to time. Hence the sentence 'l'm in a hurry.' is present in the context, we can assume that the waiter intentionally misinterprets the word 'long' creating a humorous situation.

A: Why are the lawyers all uneasy sleepers?

$B$ : Because they lie first on one side, and then on the other, and remain wide awake all the time.

(Gao C., 2013, p.669)

The word 'lie' can be interpreted as a) put one's body in a resting position on a horizontal surface, and b) make a statement one knows to be untrue. The first refers to the sleeping state, while the second refers to the engagement of lawsuit.

\section{A: Did you take a bath? \\ B: No, only towels, is there one missing? \\ (Giorgadze M., 2014, p.274)}

In this joke, ambiguity arises due to semantic meaning of set expression 'take a bath' which means 'have a shower', whereas direct meaning of the verb 'take' is 'carry something from one place to another'.

Girlfriend's dad: Young man, it is important you understand our daughter is well reared.

Boyfriend: But there is not much wrong with her front half either.

As we see, lexical ambiguity occurs due to homonymy. The word 'rear' has two distant meanings: a) 'rear' as a verb (bring up, educate), and b) 'rear' as a noun (back part). 
Thus, in all above jokes, humorous effect and laughter are induced by lexical-semantic ambiguity and therefore, such jokes can be dubbed lexical-semantic linguistic jokes.

\subsection{Structural-syntactic Jokes}

In structural-syntactic jokes, words do not have two meanings and the humorous effect is not induced by lexical ambiguity. Here the structure can be interpreted in two different ways as in the following examples.

Administrator: We do not serve colored people.

Customer: That is fine by me. I just want some roast chicken.

(Ross, 2005, p.23)

In this joke not a single word has two meanings. The phrase 'colored people' is used as indirect object by the administrator but it is understood as direct object by the customer whose reply induces laughter.

A: Let us eat up the street.

B: No, thanks. I do not like concrete.

(Sanchez Roura, 1995, p.211)

Again not a single word has two meanings in the above joke. Yet, the humorous effect occurred due to structural ambiguity. The first interlocutor referred 'up' to the word 'street' (up the street), but the second one interpreted it as if 'up' referred to the verb 'eat' (eat up)

\section{A: I did not sleep with my wife before we were married, did you?}

B: I do not know. What was her maiden name?

(Ross, 2005, p.40)

As no word has two meanings in this joke, it can be considered structural-syntactic one. Humorous effect arises here due to omission of the second object in the utterance of the first interlocutor. If he said 'did you do it with yours?' instead of 'did you?', there would be no ambiguity and humorous effect.

\section{A: I rushed out and killed a huge lion in my pajamas.}

B: How did the lion get in your pajamas?

(Seewoester, 2009, p.9)

In this joke, the structural ambiguity is evident. The first interlocutor uses the phrase' in my pajamas' as an adverbial modifier of manner, while the second one interprets that phrase as an adverbial modifier of place.

Lady: Must I stick the stamp on myself?

Clerk: You will accomplish more, madam, if you stick it on the package.

(Lew, 1996, p.34)

This joke is a structural-syntactic one, since the ambiguous part has two different structures depending upon whether 'on' refers to the verb 'stick' (stick on), or to the pronoun 'myself' (on myself).

\section{VIOLATION OF GRICE'S MAXIMS AND HUMOR ANALYSIS}

\subsection{Violation of Grice's Maxims}

As it was mentioned above, American philosopher Paul Grice maintains that people follow certain principles to conduct successful interaction and avoid misunderstanding. Grice summarizes these principles in the form of four super maxims.

1. Maxim of quantity: make your contribution as informative as required (for the current purpose of exchange). Do not make your contribution more informative than required.

2. Maxim of quality: do not say what you believe to be false. Do not say that for which you lack adequate evidence.

3. Maxim of relation: be relevant.

4. Maxim of manner: avoid obscurity of expressions, avoid ambiguity, be brief (avoid unnecessary prolixity), and be orderly. (Grice, 1975, p.45-46)

According to Grice, the above four super maxims can be violated in the following four ways:

1. Quietly and unostentatiously

A: Do you love me?

B: Yes. 
Supposing speaker B does not love really, he quietly violates the maxim of quality.

2. By opting out a maxim

A: How much are you paid per month?

B: Sorry, that is confidential.

This is explicit information given by the speaker B that maxim of quantity cannot be satisfied.

3. Coping with a clash between maxims

A: Where was that poet born?

B: Somewhere in the South.

The speaker B does not know exactly where the poet was born. To avoid violating the maxim of quality providing information he knows to be untrue - he violates the maxim of quantity - providing less information than that was asked for.

4. Flouting a maxim in order to exploit it.

A: John is the CEO of the company, is he not?

B: Uh-huh, and I am the Emperor of Japan.

Speaker B, unlike someone who simply violates the maxim, flouts the maxim (here the maxim of quality) and expects the listener to notice it. (Grice, 1975, p. 49)

\subsection{Analysis of Jokes According to Grice's Maxims}

As it has already been noted, the humorous effect in all above jokes is based on either lexical-semantic or structural ambiguity. Therefore, it can be claimed that in all jokes of this type, Grice's maxim of manner (avoid ambiguity) is violated. It is easily noticed that the jokes of this type usually consist of two lines; the first one being a statement or a question, and the second one being a response to it. As it is the first line that contains ambiguity, we can conclude that the violation of manner maxim takes place there. In addition, it seems that the maxim of quantity is also violated in the first line. Because if a single word or phrase that contains clarifying information is added to the first line, ambiguity can be avoided. The other two maxims, i.e. the maxim of quality and the maxim of relation are not violated in the first line. Because the first interlocutor, who opens the conversation, does not say anything that he believes to be false (maxim of quality) or irrelevant (maxim of relation). It is the second interlocutor, whose irrelevant response induces humorous effect and laughter, intentionally or unintentionally violates the maxim of relation. Besides, there are cases where only the second line contains ambiguity (e.g. as in the above joke about lawyers) and violates the maxim of manner. Thus, in the second line of such jokes, the maxim of quantity and the maxim of quality are not violated as the humorous effect and laughter are induced irrelevant answer or ambiguity, but not by short (not informative enough) answer or a lie. To sum up, Grice's maxims of quantity and manner are violated $d$ in the first line, and the maxims of relation and manner are violated in the second line of two linear linguistic jokes.

As to the manner of violation of Grice's maxims in above jokes, analysis revealed that maxim of quantity and manner are violated quietly and unostentatiously, whereas the maxim of relation is violated by flouting. None of Grice's super maxims is violated by opting out or coping with a clash between two maxims in above analyzed jokes.

\section{CONCLUSIONS AND FUTURE STUDY}

Having analyzed randomly chosen verbal linguistic English jokes according to the types of ambiguity inducing humorous effect and to violation of Grice's maxims in these jokes, we come to the following conclusions:

In linguistic jokes, the humorous effect is achieved through lexical-semantic or structural-syntactic ambiguity where Grice's maxims are violated as follows:

a) In the first line of such two linear verbal linguistic jokes Grice's maxims of quantity (make your contribution as informative as required) and manner (avoid ambiguity) are violated.

b) In the second line of such jokes, Grice's maxims of relation (be relevant) and manner (avoid ambiguity) are violated. 
Grice's maxims are violated in the following ways:

a) Maxims of quantity and manner are violated quietly and unostentatiously.

b) Maxim of relation is violated by flouting the maxim in order to exploit it.

Grice's maxim of quality (do not say what you believe to be false) is not violated in any of the analyzed jokes.

The violation of Grice's maxims does not take place by opting out of a maxim, or by coping with a clash between two maxims in the above jokes.

The present study paves the way for future studies in terms of finding out deeper relationship between types of ambiguity in verbal linguistic jokes on the one hand, and the violation of Grice's maxims in these jokes and the manner of this violation on the other.

Studying the relationship between these two phenomena, viz. linguistic ambiguity and Cooperative principles, can give an insight into the nature of linguistic jokes particularly, and humor generally.

\section{REFERENCE LIST}

Attardo S., H. Attardo, D. Baltes P., \&Petray, M.J. (1994). The Linear Organization of Jokes: Analysis of Two Thousand Texts. Humor: International Journal of Humor Research 7(1), 27-54.

Crystal D.,(2008). A Dictionary of Linguistics and Phonetics $6^{\text {th }}$ Edition. Oxford: Blackwell Publishing.

Gao Chao, (2013). A Pragmatic Study of Ambiguity and Puns in English Humor. $2^{\text {nd }}$ International Conference on Management Science and Industrial Engineering. 666-669.

Giorgadze M., (2014). Linguistic Features of Pun, Its Typology and Classification. European Scientific Journal, Special edition, vol.2, 271-275.

Grice P., (1975). Logic and Conversation. Syntax and Semantics 3, 41-58.

Lew R., (1996). An Ambiguity-based Theory of the Linguistic verbal Jokes in English. Doctor's Thesis, Adam Mickiewicz University.

Sanchez Roura, (1995). Syntactic Ambiguity as a Device in British Humour. Revista Alicantina de Estudios Ingleses, 8, 209-228.

Ross A.,(2005). The Language of Humor, London \& New York, Routledge.

Seewoester S.,(2009). Linguistic Ambiguity in Language-based Jokes. Master's Thesis, DePaul University. 